\title{
Survey the Effect of the Extraction from the Seed of Annona squamosa L. with Ethanol and the Chitosan on the Ziziphus mauritiana Lamk Storage
}

\author{
Dam Sao Mai*, Lam Thi Thuong and Trinh Xuan Ngo \\ Institute of Biotechnology and Food Technology, Ho Chi Minh University of Industry, 12 Nguyen Van Bao Str., Ho Chi Minh City, \\ Vietnam \\ *Corresponding author’s e-mail: damsaomai@yahoo.com
}

\begin{abstract}
Ziziphus mauritiana L. belongs to Rhamnaceae Z. mauritiana L. consisting of 81\%-97\% pulp and easy to spoil (about 4-5 days in the natural environment). The seed of Annona squamosa L. consists of annonaceous acetogenins which affects on some bacterium, fungi and insects. This survey focuses on the Ziziphus mauritiana L. storage when it was using the extraction from the seed of Annona squamosa L. with ethanol 95\% and the chitosan. The quality of Ziziphus mauritiana L. under the storage time was tested via the reducing weight, the reducing sugar, vitamin $\mathrm{C}$ and total soluble solid. The storage temperature was $25{ }^{\circ} \mathrm{C}$. The control samples were tested when using only the extraction from the seed of Annona squamosa L. with ethanol 95\% or using only the chitosan. The best result was when the samples were stored under the condition of $120 \mathrm{~g} / \mathrm{L}$ of the extraction from the seed of Ziziphus mauritiana L. combining with $1 \%$ chitosan in 8 days. After 8 days storage, the surveyed products lost $9.31 \%$ weight; had $5.06 \%$ reducing sugar, $0.0167 \%$ vitamin $\mathrm{C}$, and $8.86 \%$ total soluble solid.
\end{abstract}

Key words: Annona squamosa L., Ziziphus mauritiana L., chitosan, storage, annonaceous acetogenins. 